\title{
Spinal Anesthesia Versus General Anesthesia for Elective Lumbar Spine Surgery: A Randomized Clinical Trial
}

\author{
Dr.Asaad Hatem Aziz Alaouadi. \\ Iraqi board in anesthsia and icu F.I.B.M.S.A
}

\section{Abstract \\ BACKGROUND}

Either general or regional anesthesia can be used for lumbar disk surgery. The common anesthetic technique is general anesthesia (GA). The aim of this study was to compare the intra and postoperative outcomes of spinal anesthesia (SA) with GA in these patients.

\section{METHOD:}

Seventy-two patients were enrolled in the study. They were randomized into two groups with 37 patients in GA Group and 35 ones in SA Group. The heart rate (HR), mean arterial pressure (MAP), blood loss, surgeons satisfaction with the operating conditions, the severity of postoperative pain based on visual analogue scale (VAS) and analgesic use were recorded.

\section{RESULTS:}

The mean blood loss was significantly less in the SA Group compared to GA Group $(p<0.05)$. Intraoperative maximum blood pressure and heart rate changes were significantly less in SA Group $(\mathrm{p}<0.05)$. The surgeons satisfaction was significantly more in the SA Group $(\mathrm{p}<0.05)$. The number of patients who used postoperative analgesic as well as postoperative mean VAS was significantly less in SA Group in comparison with GA group $(\mathrm{p}<0.05$ for both

\section{CONCLUSIONS:}

Our study showed that SA was superior to GA in providing postoperative analgesia and decreasing blood loss while maintained better perioperative hemodynamic stability without increasing adverse side effects.

KEYWORDS: Anesthesia, General, Spinal, Lumbar Surgery

DOI: $10.7176 / \mathrm{JHMN} / 88-04$

Publication date: April $30^{\text {th }} 2021$

Surgery on the lower thoracic and lumbar spine can be safely performed under general or regional anesthesia. Patients satisfaction and the ability to carry out prolonged operations in the prone position without airway compromise are of advantages of using general anesthesia (GA).1,2 Alternatively, the most important advantages of regional anesthesia are the decrease in intraoperative blood loss and consequently improving operating conditions, 3 the decrease in perioperative cardiac ischemic incidents, postoperative hypoxic episodes, arterial and venous thrombosis, and to provide proper postoperative pain control.4-7 Additionally, in order to prevent brachial plexus injury and pressure necrosis of face, it is better if patients can position themselves while they are awake. This is possible only with spinal anesthesia (SA.(

As Scott et al8 showed, pulmonary complications were more common in patients underwent GA compared with regional anesthesia. Two retrospective studies shown that SA resulted in better outcome compared with GA in patients underwent surgeries on lumbar spine.9,10

An acceptable anesthetic technique must have characteristics such as rapid onset and reversal of effects. Also, it must maintain stable hemodynamic during operation without need to increase blood transfusion. Lastly, an excellent anesthetic must decrease recovery room stay while reduce postoperative pain, nausea, vomiting, and requirement for additional analgesics. As our search in medical literature showed, there are controversies whether SA or GA offers these advantages for lumbar disk surgery. Sadrolsadat et all1 showed that in contrast to the previous studies that revealed SA was better than GA for patients undergoing lower thoracic and lumbar spine surgery, SA had no advantages over GA. They also showed that SA accompanied with more adverse effects compared with GA. They emphasized that further study must be performed before final conclusion elucidated.

In the clinical experience, it seems to the authors that patients who underwent lumbar spine surgery with SA have more satisfaction with lower adverse effect compared with those with GA. This is in accordance with the most previous studies but is opposite to Sadrolsadat et al study. For more clarification of this important topic, we designed to run the present study to evaluate both intraoperative and postoperative outcomes after SA or GA techniques, when employed in patients undergoing lumbar spine surgery.

\section{Methods}

Seventy-two patients, in AL-Zarah teaching hospital in AL-Kut aged 18-60 years old who were scheduled for discectomy, laminectomy, for aminotomy or cord tumor were selected. Patients with history of seizure or 
intracranial hypertension, contraindication for spinal anesthesia (such as patients refusal, coagulopathy, infection at site of needling, hypovolemia), severe spinal stenosis, a near complete or total myelographic block, myelographic demonstration of arachnoiditis, inadvertent production of high spinal, drug or alcohol abuse were excluded. If patients had any changes in surgical technique or massive bleeding during operation which needed blood transfusion, they also excluded from the study. Eligible candidates were given written informed consent. The study protocol was approved by our institute Ethics Committee. The study was performed in Isfahan Alzahra Hospital from April 2009 to April 2010. The sample size was estimated based on a power calculation which showed that at least 30 patients per group were necessary to achieve $80 \%$ power to detect a $20 \%$ difference between two groups in the VAS scoring with $\alpha$ equal to 0.05 .

All surgeries were carried out by the same surgeon. Patients were randomly allocated into GA or SA groups using sealed envelopes with 37 and 35 patients in each group respectively.

No premedication was given to the patients. In GA group, patients were anesthetized with Propofol (2 $\mathrm{mg} / \mathrm{kg}$ IV), Lidocaine $(1.5 \mathrm{mg} / \mathrm{kg})$, and Fentany $(1.5 \mu \mathrm{g} / \mathrm{kg} \mathrm{IV})$. Endotracheal intubation was facilitated with Atracurium $(0.6 \mathrm{mg} / \mathrm{kg} \mathrm{IV})$. Anesthesia was maintained with $1.2 \%$ Isoflurane and Nitrous Oxide $50 \%$ in Oxygen. Morphine $(10 \mathrm{mg})$ was administered for intraoperative analgesia. Subsequently, the patients were properly placed onto a prone position, arms resting on the arm boards while they were flexed 90 degrees at elbow. For prevention of pressure on nose and globe of the eyes, the faces placed on a smooth brace.

The heart rate, systolic, diastolic, mean arterial blood pressure, and oxygen saturation were monitored every 15 minutes throughout the surgery using ECG, noninvasive blood pressure monitoring and pulse oximetry. After termination of operation, the anesthetic drugs were discontinued after patients received $100 \%$ oxygen. Subsequently, neuromuscular blockade was reversed by using Neostigmine $0.04 \mathrm{mg} / \mathrm{kg}$ and Atropine $0.02 \mathrm{mg} / \mathrm{kg}$. The trachea was extubated and patients transferred to the postanesthesia care unit (PACU) if patients had spontaneous respiration, pulse oximeter oxygen saturation more than 95\%, end-tidal carbon dioxide 35-40 $\mathrm{mmHg}$, respiratory rate less than 30 per minutes, and tidal volume more than $5 \mathrm{ml}$ per kilogram.

In SA group, the block was done with $3.0-3.2 \mathrm{ml} 0.5 \%$ Bupivacaine in an $8.5 \%$ Dextrose solution combined with $25 \mu \mathrm{g}$ Fentanyl after preloading patients with $7 \mathrm{ml} / \mathrm{kg}$ Lactated Ringer's solution over 10-15 minutes. Thereafter, the patients were placed into a sitting position and preparing and draping were done. Spinal anesthesia was performed using a 25-gauge Quincke spinal needle at either the L4 or L5 interspace after local infiltration of 2-3 $\mathrm{ml}$ of $2 \%$ Lidocaine. After observing spinal fluid, Bupivacaine and Fentanyl was administered into intrathecal space and patients were placed in supine position. Five to ten minutes after establishment of spinal level of block (which usually occurred between T-6 and T-10), the patients were placed into prone position. Oxygen at $2 \mathrm{~L} / \mathrm{min}$ via nasal cannula was administered afterwards.

Throughout the surgery, if the patients had bradycardia (heart rate less than 60 per minutes) or hypotension (systolic blood pressure less than $90 \mathrm{mmHg}$ ), $0.5 \mathrm{mg}$ Atropine or $5 \mathrm{mg}$ Ephedrine was administered. Throughout the surgery, sedation of patients was done by a Propofol infusion of $25-50 \mu \mathrm{g} / \mathrm{kg} / \mathrm{min}$ IV. At the end of surgery, the Propofol was discontinued and the patient was turned from the prone position to supine were transferred to the PACU.

At the time of patient arrival to the operating room, age, sex, height, weight, and ASA physical status were recorded. Throughout the administration of anesthetics, maximum heart rate and mean arterial blood pressure changes compared to the baseline were recorded. Blood loss was monitored and recorded by calculating the volume of blood suctioned from the surgical field. Postoperative analgesic use and total administered dosage of Meperidine were recorded till 24 hours after surgery. In addition, the incidence of nausea was recorded. Intravenous Metoclopramide at $0.1 \mathrm{mg} / \mathrm{kg}$ IV was administered to patients with vomiting and for nausea if lasted more than 10 minutes. If the VAS score was more than $40 \mathrm{~mm}$, then $0.4 \mathrm{mg} / \mathrm{kg}$ Meperidine was given intravenously and, if the score did not reduce within 10 minutes, an additional $0.2 \mathrm{mg} / \mathrm{kg}$ was administered and the total Meperidine consumption was recorded.

The patients and surgeon satisfaction was also evaluated as a dichotomized factor (Yes or No). Duration of surgery (the time from beginning surgery to the closure of wound by the last suture) and duration of recovery stay (the time from arrival to the PACU to discharge from it) were recorded. If patients were awake and had no pain, nausea, vomiting, or hemodynamic instability, they were discharged from PACU in Group GA. In Group SA, when patients had no pain, nausea, vomiting, and at least two segment regression of spinal block, they were discharged from the PACU.

Data are presented as mean \pm SD or number (percent). Age, weight, height, maximum blood pressure and heart rate changes, duration of surgery, duration of recovery stay, and blood loss were compared between two groups using Student's t-test. Sex, ASA physical status, patients and surgeon satisfaction, postoperative analgesic use, and complication rates were assessed by Pearson chi-square test or Fisher's exact test if needed. P-value $<$ 0.05 was considered statistically significant. All statistical analyses were done using SPSS ver.16.0. 


\section{Results}

There was no significant difference between two groups with respect to demographic characteristics, duration of surgery and PACU stay (Table 1). Intra-operative maximum mean arterial blood pressure and heart rate changes were significantly less in SA compared with GA $(\mathrm{p}<0.05)$ (Table 2).(

Table 1

Patient characteristic, duration of surgery and recovery stay in two groups

\begin{tabular}{lcc}
\hline Variable & $\begin{array}{c}\text { Group SA } \\
(\mathrm{n}=35)\end{array}$ & $\begin{array}{c}\text { Group GA } \\
(\mathrm{n}=37)\end{array}$ \\
\hline Age (year) & $42.1 \pm 3.1$ & $45.1 \pm 2.9$ \\
Sex (M/F) & $22 / 13$ & $20 / 17$ \\
ASA (III) & $11 / 24$ & $15 / 22$ \\
Weight (Kg) & $75.0 \pm 4.0$ & $72.0 \pm 3.8$ \\
Height (cm) & $161.0 \pm 7.0$ & $158.0 \pm 5.0$ \\
Duration of surgery (min) & $115.0 \pm 3.2$ & $111.0 \pm 7.4$ \\
Duration of recovery stay (min) & $55.0 \pm 6.7$ & $50.0 \pm 5.9$ \\
\hline
\end{tabular}

Values are presented as mean \pm SD or number. SA: Spinal anesthesia; GA: General anesthesia. No significant difference was noted between two groups

Table 2

Intra-operative and postoperative outcomes in two groups

\begin{tabular}{lccc}
\hline Variable & $\begin{array}{c}\text { Group SA } \\
(\mathbf{n}=\mathbf{3 5})\end{array}$ & $\begin{array}{c}\text { Group GA } \\
(\mathbf{n}=\mathbf{3 7})\end{array}$ & P value \\
\hline Maximum mean arterial blood pressure changes $(\mathrm{mmHg})$ & $-25.1 \pm 4.2$ & $+21.0 \pm 6.7$ & $<0.05$ \\
Maximum heart rate changes (mmHg) & $-13.2 \pm 3.9$ & $+17.5 \pm 5.5$ & $<0.05$ \\
Blood loss (mL) & $210 \pm 40$ & $350 \pm 35$ & $<0.05$ \\
Surgeon satisfaction & $35(100)$ & $30(81.8)$ & $<0.05$ \\
Patients satisfaction & $35(100)$ & $25(67.6)$ & $<0.05$ \\
Postoperative analgesic use & $0(0)$ & $6(16.2)$ & $<0.05$ \\
Total Meperidine use (mg) & $0(0)$ & $150 \pm 6.4$ & $<0.05$ \\
Postoperative nausea & $2(5.7)$ & $1(2.7)$ & $>0.05$ \\
\hline
\end{tabular}

Values are presented as mean \pm SD or number (\%). SA: Spinal anesthesia; GA: General anesthesia

Blood loss was significantly less in SA group compared with GA group $(\mathrm{p}<0.05)$ (Table 2$)$. Surgeon and patients satisfaction were significantly more in SA compared with GA $(\mathrm{p}<0.05)$ (Table 2$)$. (

Postoperative analgesic use and total Meperidine use was significantly less in SA group compared to GA group $(p<0.05)$. The incidence of postoperative nausea was not significantly different in two groups (Table 2$)$. There were no patients with hypotension or bradycardia in SA or GA groups.

\section{Discussion}

Spinal, epidural or general anesthesia have been performed for lower spine surgery, but limited randomized controlled prospective investigations have been carried out to establish whether one of these procedures is better in decreasing peri-operative complications.

McLain et al12 in a case-controlled study in 400 patients underwent either spinal anesthesia or general anesthesia for performing lumbar decompression, showed that SA was as effective as GA. They concluded that SA caused shorter anesthesia duration, decreased incidence of nausea and analgesic needs, and accompanied with fewer adverse effects. The findings of McLain et al study were in contrast with Sadrolsadat et al11 study that showed SA had no advantages over GA. Furthermore, they concluded that GA can decrease adverse effects accompanied with technique of anesthesia. They requested further clinical trial studies to verify their results.

In retrospective chart review, Tetzlaff et al13 investigated the outcomes of a large series of elective lumbar spine surgical procedures which performed under SA or GA. They concluded that SA can considered as an effective alternative to GA for lumbar spine surgery as it had lower incidence of minor complications. Their study was retrospective and they emphasized doing a prospective randomized clinical trial study for documentation of their results.

The present study showed that SA may be better compared to GA. SA diminished blood loss, maximum blood pressure and heart rate changes, and postoperative analgesic use. In addition, surgeon and patients satisfaction was significantly more in SA. All procedures were performed with the same neurosurgeon and the anesthesia was constantly performed with meticulous obedience to the practice and consequently confounding 
variables effects were avoided.

As previous studies showed, SA reduced blood loss for lower limb orthopedic and vascular surgeries compared to GA.14-17 Lumbar spine surgery under epidural anesthesia was associated with decreased blood loss compared with general anesthesia.18 The results of our study confirm these conclusions. SA presumably decreases blood loss by two mechanisms. One mechanism is vasodilatation and hypotension caused by sympathetic blockade.19 Patients under SA have spontaneous ventilation which causes lower intrathoracic pressure and consequently less distension of epidural veins. This is another and more important mechanism of decreasing bleeding after SA.19 This finding that maximum intraoperative mean arterial blood pressure and heart rate changes over the basal value were significantly less in Group SA is not unexpected, because SA prevents the increase in stress hormones better than GA.20-25

SA improved postoperative conditions of patients due to decreasing pain and need to the analgesia. Hassi et al10 showed that patient satisfaction was high with a low level of complications in SA. Nevertheless, their study was retrospective and did not compare it with the other anesthetic techniques. They, nonetheless, emphasize a general patient satisfaction with SA that was also described in our study.

Two different mechanisms can explain decreasing postoperative analgesic use in the SA.One mechanism is the preemptive effect of SA that decreases the pain scores by preventing afferent nociceptive sensitization pathway.18 Lower analgesic requirement after operation pointed out such an effect. The second mechanism is probably existence of some residual sensory blockade in SA group. This is due to lagging of sensory recovery behind motor recovery

\section{References}

1. Cucchiara RF, Michenfelder JD. Clinical Neuroanesthesia. London: Churchill Livingstone; 1990. Vertebral column and spinal cord surgery; pp. 325-50

2. Abrishamkar S, Aminmansour B, Arti H. The effectiveness of computed tomography scans versus magnetic resonance imaging for decision making in patients with low back pain and radicular leg pain. Journal of Research in Medical Sciences. 2006;11(6):351-4. ]

3. Modig J, Karlstrom G. Intra- and post-operative blood loss and haemodynamics in total hip replacement when performed under lumbar epidural versus general anaesthesia. Eur J Anaesthesiol. 1987;4(5):345-55.

4. Rodgers A, Walker N, Schug S, McKee A, Kehlet H, van Zundert A, et al. Reduction of postoperative mortality and morbidity with epidural or spinal anaesthesia: results from overview of randomised trials. BMJ. 2000;321(7275):1493. [

5. Urwin SC, Parker MJ, Griffiths R. General versus regional anaesthesia for hip fracture surgery: a metaanalysis of randomized trials. Br J Anaesth. 2000;84(4):450-5.

6. Indelli PF, Grant SA, Nielsen K, Vail TP. Regional anesthesia in hip surgery. Clin Orthop Relat Res. 2005;441:250-5.

7. Sakura S. Epidural anesthesia and spinal anesthesia in the elderly. Masui. 2007;56(2):130-8. [In Japanese]

8. Scott NB, Kehlet H. Regional anaesthesia and surgical morbidity. Br J Surg. 1988;75(4):299-304.

9. Ditzler JW, Dumke PR, Harrington JJ, Fox JD. Should spinal anesthesia be used in surgery for herniated intervertebral disk. Anesth Analg. 1959;38(2):118-24.

10. Hassi N, Badaoui R, Cagny-Bellet A, Sifeddine S, Ossart M. Spinal anesthesia for disk herniation and lumbar laminectomy. Apropos of 77 cases. Cah Anesthesiol. 1995;43(1):21-5. [In French]

11. Sadrolsadat SH, Mahdavi AR, Moharari RS, Khajavi MR, Khashayar P, Najafi A, et al. A prospective randomized trial comparing the technique of spinal and general anesthesia for lumbar disk surgery: a study of 100 cases. Surg Neurol. 2009;71(1):60-5.

12. McLain RF, Kalfas I, Bell GR, Tetzlaff JE, Yoon HJ, Rana M. Comparison of spinal and general anesthesia in lumbar laminectomy surgery: a case-controlled analysis of 400 patients. $J$ Neurosurg Spine. 2005;2(1):17-22.

13. Tetzlaff JE, Dilger JA, Kodsy M, al Bataineh J, Yoon HJ, Bell GR. Spinal anesthesia for elective lumbar spine surgery. J Clin Anesth. 1998;10(8):666-9.

14. Thorburn J, Louden JR, Vallance R. Spinal and general anaesthesia in total hip replacement: frequency of deep vein thrombosis. Br J Anaesth. 1980;52(11):1117-21.

15. Davis FM, McDermott E, Hickton C, Wells E, Heaton DC, Laurenson VG, et al. Influence of spinal and general anaesthesia on haemostasis during total hip arthroplasty. Br J Anaesth. 1987;59(5):561-71.

16. Cook PT, Davies MJ, Cronin KD, Moran P. A prospective randomised trial comparing spinal anaesthesia using hyperbaric cinchocaine with general anaesthesia for lower limb vascular surgery. Anaesth Intensive Care. 1986;14(4):373-80.

17. Greenbarg PE, Brown MD, Pallares VS, Tompkins JS, Mann NH. Epidural anesthesia for lumbar spine surgery. J Spinal Disord. 1988;1(2):139-43.

18. Covino BG. Rationale for spinal anesthesia. Int Anesthesiol Clin. 1989;27(1):8-12. 
19. Kehlet H. The stress response to surgery: release mechanisms and the modifying effect of pain relief. Acta Chir Scand Suppl. 1989;550:22-8.

20. Davis FM, Laurenson VG, Lewis J, Wells JE, Gillespie WJ. Metabolic response to total hip arthRroplasty under hypobaric subarachnoid or general anaesthesia. Br J Anaesth. 1986;59(6):725-9.

21. Pflug AE, Halter JB. Effect of spinal anesthesia on adrenergic tone and the neuroendocrine responses to surgical stress in humans. Anesthesiology. 1981;55(2):120-6.

22. Pflug AE, Aasheim GM, Foster C. Sequence of return of neurological function and criteria for safe ambulation following subarachnoid block (spinal anaesthetic) Can Anaesth Soc J. 1978;25(2):133-9.

23. Hebl JR, Horlocker TT, Kopp SL, Schroeder DR. Neuraxial blockade in patients with preexisting spinal stenosis, lumbar disk disease, or prior spine surgery: efficacy and neurologic complications. Anesth Analg. 2010;111(6):1511-9.

24. Basaranoglu G, Erkalp K, Saidoglu L, Aydas D, Ozdemir H, Teker M. Selective spinal anesthesia for limb amputation above knee level. J Clin Anesth. 2011;23(2):169.

25. Limongi JA, Lins RS. Cardiopulmonary arrest in spinal anesthesia. Rev Bras Anestesiol. 2011;61(1):110-20. 